\title{
PERDA PROGRESSIVA DE MEMÓRIA EM PACIENTES RECUPERADOS DA SARS-COV-2/ COVID-19
}

\author{
PROGRESSIVE MEMORY LOSS IN PATIENTS RECOVERED FROM SARS-COV-2 \\ / COVID-19
}

\author{
Fabiano de Abreu Rodrigues ${ }^{1}$ \\ Míriam da Silva Pinto $^{2}$ \\ Angélica de Sousa ${ }^{3}$ \\ Milena Teresa Ataídes da Silva ${ }^{4}$ \\ Roselene do Espírito Santo Wagner ${ }^{5}$
}

RESUMO: Mesmo anulando a hipótese da Sars-CoV-2 / Covid-ı9, já estávamos a sofrer devido às dificuldades na memorização. A cultura de um povo, vinculada à ansiedade e como esta é conduzida, bem como os fatores genéticos, são precursores para as consequências/sintomas que podemos observar em pacientes recuperados da Covid-19, entre eles, dificuldade de concentração, raciocínio e memória. Neste artigo, de forma resumida por meio de pesquisa bibliográfica nas bases de dados, relata-se a relação do novo coronavírus Covid-19, com o sistema nervoso central, que pode resultar em sequelas permanentes ou progressivas no foco atencional, compreensão, memória e forma de reversão deste quadro mediante a neuroplasticidade cerebral. Efeitos da infecção podem ser vistos na relação com os episódios de trombose, AVC,

\footnotetext{
I Logos University International, UniLogos. Doutor em neurociências pela Logos University International; Doutor e Mestre em Psicologia da Saúde pela Université Libre des Sciences de l'Homme de Paris Mestre em Psicanálise pelo Instituto Gaio; com formações em psicologia e neuropsicologia; Jornalista e Filósofo integrante da SPN - Sociedade Portuguesa de Neurociências 814, da SBNEC - Sociedade Brasileira de Neurociências e Comportamento - 6028488 e da FENS Federation of European Neuroscience Societies - PT30079 deabreu.fabiano@gmail.com

2 Mestranda em Neurociências (Unilogos), Mestranda em Educação e Ciência (WCU), Neuropsicopedagogia, Psicologia e Psicanálise (Metropolitana -SP), Neuropedagogia e Psicanálise (Faculdade Ávila), Métodos e Técnicas de Ensino (Universo), Inclusão em AEE (Fabec), Pedagogia (UEG).mdmisilva@gmail.com.

3 Mestranda em Neurociências Unilogos, Psicóloga, Especialista em Psicologia do Trânsito angelicas.psicologa@gmail.com.

4 Mestranda em Neurociências Unilogos,Psicóloga, Especialista em Teoria Cognitivo Comportamental.milenateresapsiz@gmail.com

${ }^{5}$ Doutoranda EBWU- Psicologia da Educação, Doutoranda Unilogos - Saúde Coletiva com Ênfase em Neurociência Mestre em Psicanálise- Faculdade Gaio- SP, Neuropsicóloga- Universidade Estácio de Sá, Psicologa Clínica- Universidade Estácio de Sá, Psicanalista Clinica- Reg. 7o.II SBPC (Sociedade Brasileira de Psicanálise), Extensão em Psiquiatria para Dependência Química -Puc /Clínica Jorge Jaber/RJ, Perita Judicial em Psicologia - Curso Beta SP, Psicóloga Bariátrica- Saúde Metabólica- RJ, Psicóloga do Psicóloga do Desenvolvimento Vital- Faculdade Cândido Mendes-RJ, Formação em Neurociências e Comportamento - Faculdade Gaio SP, Formação em Perícia em Serviço Social e Psicologia - Faculdade Gaio SP. leninhaespiritosanto@hotmail.com
} 
insuficiência renal e cardíaca, fibrose pulmonar, entre outros fatores, mas, o estudo se delineará na neurociência, especificamente na memória.

Palavras-chaves: Sars-CoV-2. Respiração. Perda de Memória. Neuroplasticidade.

ABSTRACT: Even nullifying the hypothesis of Sars-CoV-2 / Covid-i9, we were already suffering due to difficulties in memorization. The culture of a people, linked to anxiety and how it is conducted, as well as genetic factors, are precursors to the consequences/symptoms that we can observe in patients recovered from Covid-ig, including difficulty in concentration, reasoning, and memory. In this article, we briefly report the relationship of the new Covid-ig coronavirus with the central nervous system, which can result in permanent or progressive sequelae in the focus of attention, understanding, memory and reversal of this condition through brain neuroplasticity. Effects of infection can be seen in relation to episodes of thrombosis, stroke, kidney and heart failure, pulmonary fibrosis, among other factors, but the study will be outlined in neuroscience, specifically in memory.

Keywords: SARS-CoV-2. Neuroplasticity. Breathing. Memory loss.

\section{INTRODUÇÃO}

O ano de 2020 foi o ano que o mundo "parou" por causa da pandemia da Covid-19. Pesquisadores do mundo todo enfrentavam uma batalha para desvendar um vírus pouco conhecido que agregava sintomas sistêmicos que causava no corpo humano, febre, dores no corpo, perda de paladar (ageusia), perda de olfato (anosmia/hiposmia), perda da percepção do cheiro (anosmia), suas mutações e variedades de novos sintomas. Um dos sistemas envolvido na tão falada síndrome pós-COVID é o Sistema Nervoso Central e Periférico.

A virada do ano nunca foi tão desejada, muitos achavam que o ano de 2021 seria a cura para o ano de 2020, porém nunca poderíamos imaginar que iríamos debruçar sobre mais um mistério da Sars-Cov-2, agora, a síndrome pós-covid.

Em abril de 2020, já havia rumores que a Covid-ı poderia ser uma das causas de muitas disfunções neurológicas de pacientes que foram contaminados por seu vírus. Nesse mesmo período já havia muitos artigos, alguns deles ainda não revisados, como os dos estudos da China que apontavam muitos pacientes curados, mas, que apresentavam problemas neurológicos, sendo o ponto de partida para que os pesquisadores da USP e da Universidade de Univille fizessem uma revisão nãosistemática desses artigos.

Apesar de inconclusivas, as inúmeras pesquisas e estudos de casos, dos quais apresentaremos alguns, corroboram para a hipótese de que memória, respiração e a doença em questão, estão mais interligadas do que se parece e considera-se que a resposta, para tal problema, deva estar inteiramente ligada ao fato de que o cérebro é 
plástico, podendo recuperar o funcionamento mediante práticas que favoreçam a Neuroplasticidade.

\section{CONTEXTUALIZAÇÃO DA COVID-ıg E A PERDA DE MEMÓRIA}

No cérebro e Sistema Nervoso Central (SNC), as sequelas neurológicas podem causar danos severos em função das infecções virais respiratórias. Os pesquisadores brasileiros analisaram um artigo que foi publicado por Ling Mao, do Departamento de Neurologia do Union Hospital, Faculdade de Medicina de Tongji da Universidade de Ciências e Tecnologia de Huazhong na China, com dados coletados entre I6 de janeiro e I9 de fevereiro de 2020, onde 214 paciente diagnosticados com Covid-ı apresentavam manifestações neurológicas que foram colocadas nas seguintes categorias:

I-Sistema Nervoso Central (tontura, dor de cabeça, ataxia, convulsão, consciência prejudicada e doença cerebrovascular);

2-Sistema Periférico (Dor nos nervos, deficiência de paladar, de olfato e visão);

3- Esquelética, que se manifestavam em lesão muscular.

Em abril de 2020, foi publicado um estudo europeu que citava uma disfunção de olfato (hiposmia) e paladar em 86 a $88 \%$ de 417 pacientes infectados. Destes, $13 \%$ descreveram sobre alucinações olfativa e $32 \%$ falta de sensibilidade no olfato (parosmia). Marcus Gonçalves, neurologista da Univille, pontua que "o que nos intriga é que, de todos os pacientes que tiveram neuropatia olfatória, apenas $40 \%$ ficaram curados após 30 dias de início dos sintomas”. Desse estudo, cerca de 80\% dos 76 pacientes que não apresentaram obstrução nasal ou rinorreia e corrimento nasal excessivo, apresentaram anosmia ou hiposmia e sintomas depressivos, sono não restaurador, déficit de memória e falta de concentração.

O Instituto do Coração (InCor) do Hospital das Clínicas da Universidade de São Paulo (USP) publicou nesse ano um estudo no qual 80\% da amostra apresentou perda de memória, dificuldade de concentração, problemas de compreensão, sonolência, falta de equilíbrio e problemas de raciocínio como sintomas recorrentes pós SARS-CoV-2. Houve ainda relatos de pessoas que tiveram problemas em funções diárias, mudanças de comportamento, emocionais e até mesmo confusão mental. Em casos mais severos pôde-se detectar sequelas cognitivas. 
A pesquisa até o momento da publicação constava com 430 participantes e permanecia recebendo voluntários. No início em 2020, tinha-se 185 pacientes que foram monitorados durante certo período. A neuropsicóloga Lívia Stocco Sanches Valentin, pesquisadora do tema utilizou de um jogo mental (MentalPlus) para avaliar as alterações neurológicas dos pacientes, obtendo como resultado: 62,7\% dos participantes tiveram a memória de curto prazo afetada e $26,8 \%$ tiveram algum sofrimento devido as alterações a longo prazo. Sequelas como essas, podem ser classificadas com a expressão braing fog (névoa cerebral), por ser uma condição que envolve perda de memória recente, dificuldades de concentração e de execução ao que era habitual às pessoas e, raciocínio lento.

Estudo de julho de 202I, publicado pela Jama Network Open, constatou o risco de sequelas, como a perda de memória, mesmo após oito meses do diagnóstico. Os pesquisadores coletaram dados demográficos, condições médicas subjacentes, sintomas, dados do RAND 36-Item Health Survey correlacionados a saúde da pessoa, problemas de memória e fatores de confusão que influenciam na perda de memória (Sorass, 202I).

Como resposta positiva ao diagnóstico teve-se o número 653, que responderam ao questionário da pesquisa 257 dias após a infecção, destes II\% relataram indícios de perda de memória. A maioria também apresentou queixas sobre pioras no quadro de saúde após a doença. Isso mostra que o SARS-CoV- 2 tem poder para impactar negativamente a memória mesmo oito meses após a pessoa ter caso leve da doença (Sorass, 2021).

\section{I Sistema Nervoso e o Sars- CoV-2}

Há a hipótese que o bulbo olfatório seja a porta de entrada da Sars-Cov-2 para acessar o sistema nervoso central, sendo o primeiro nervo craniano responsável pelas informações dos neurônios receptivos olfativos. Com a entrada por via aéreas, há comprometimento pulmonar e com isso, a baixa de oxigênio afeta o sistema nervoso central gerando dificuldades em algumas de suas funções como na coordenação motora, nas áreas da atenção, da memória e da compreensão.

Estudos demonstram que a Sars-Cov-2 pode ser capaz de adentrar o SNC utilizando o receptor da proteína transmembrana ACE2. Essa proteína é encontrada 
em diversas células do corpo, principalmente no epiléptico respiratório e sua principal função é a regulação da pressão arterial dentro do sistema Reninaangiotensina ${ }^{6}$.

Um estudo no centro médico académico Cleveland Clinic, nos Estados Unidos, publicado na revista médica “Alzheimer`s Research \& Therapy” aponta que a Covid-ı́ é capaz de provocar neuro inflamações semelhantes às causadas pela doença de Alzheimer, comprovando que o vírus pode ter impacto em vários genes ou vias envolvidas na neuroinflamação e lesão microvascular cerebral.

Uma análise de dados publicado na revista científica "The Lancet Psychiatry" com dados de 236.379 pacientes, revelou que um, a cada três infectados pelo Covid-r9, foram diagnosticados com efeitos neurológicos seis meses após a infecção. Outros estudos apontam casos de sequelas neurológicas em pessoas com outras doenças como Síndrome Respiratória Aguda Grave (Sars-CoV-I), Síndrome Respiratória do Oriente Médio (MERS) com comprometimento contínuo de memória e déficits cognitivos. Há então, relação das doenças respiratórias mais graves com o foco atencional para um processo de memorização. A névoa no cérebro, impedindo a capacidade de pensar com clareza, foram os relatos de diversos pacientes.

O Instituto de Pesquisa sobre Neurociências e Neurotecnologia (BRAIIN) conduziu um estudo com 8I voluntários que contraíram a forma leve da doença e estavam recuperados e verificou que após 60 dias dos diagnósticos, um terço dos pacientes apresentavam os seguintes sintomas: dor de cabeça (40\%), fadiga (40\%), alteração de memória (30\%), ansiedade (28\%), perda de olfato (28\%), depressão (20\%), sonolência diurna (25\%), perda de paladar (16\%) e de libido (14\%). (CRUNFLI, et al.,2020)

\subsection{Memória, atenção e respiração}

As células neuronais precisam de um fluxo ininterrupto de oxigênio para seu correto funcionamento. Alguns pacientes com SARS-CoV-2 apresentaram uma queda do nível de oxigênio sanguíneo, denominada como hipóxia silenciosa, que tem

\footnotetext{
${ }^{6} \mathrm{O}$ sistema renina-angiotensina (SRA) corresponde a um complexo sistema hormonal, cujo papel fundamental est relacionado com a homeostasia hidroeletrolìtica do organismo e o controle da PA, estimulando também a liberação de aldosterona pelo cúrtex da supra renal. (Rigatto, a Bohlke, Irigoyen, 2004)
} 
como sintomas: falta de ar, fadiga, desorientação, confusão, perda de memória, problemas cognitivos, entre outros.

\subsubsection{Respiração e Memória: qual a ligação}

Imaginar a vida humana sem a respiração tem peso tão grande ou até maior do que nossa alimentação e a supressão de necessidades básicas que nos mantêm vivos. A respiração tem como objetivo primordial a manutenção adequada dos níveis de concentração de $\mathrm{O}_{2}$, de $\mathrm{CO}_{2}$ e dos íons hidrogênicos nos tecidos. A respiração aeróbica celular é dependente do fornecimento contínuo de oxigênio e dos nutrientes que estão no meio externo, associados à remoção do dióxido de carbono.

O ser humano como um animal multicelular necessita de órgãos respiratórios especializados e associados ao sistema circulatório. Nossos pulmões, localizados anatomicamente na cavidade torácica, criam o ambiente úmido e ao mesmo tempo protegido, ideal para as trocas gasosas com o sangue, que juntamente com a bomba muscular, gerando intensidade de pressão, formam, assim, o sistema respiratório (SILVERTHORN, 2017, p. 535).

Segundo Silverthorn (2017) há quatro funções tidas como primárias ao sistema respiratório que são: I - Troca de gases entre a atmosfera e o sangue; 2 Ajustamento homeostático do $\mathrm{pH}$ corporal; 3 - Proteção contra infecções e substâncias que causam irritação ao serem inaladas e 4 - Entonações vocais.

O chamado centro respiratório é composto por diversos grupos neuronais que estão posicionados voltado para os dois lado do tronco cerebral, dividindo-se em três grupos: I - grupo respiratório dorsal, localizado na porção dorsal do bulbo, responsável pela inspiração; 2 - grupo respiratório ventral, fixo na parte ventrolateral do bulbo, incumbido da expiração; e 3 - centro pneumotáxico, situado na porção dorsal superior da ponte, para o controle da frequência e da amplitude respiratória (GUYTON E HALL, 2017, p. 1582).

O grupo respiratório dorsal de neurônios é um dos mais importantes para o controle da inspiração e do ritmo respiratório, situado em maior parte, no núcleo do trato solitário (NTS). O ritmo básico é gerado por esses neurônios, de forma rítmica e em rampa por aproximadamente 2 segundos, com interrupção abrupta de 3 segundos (GUYTON E HALL, 2017, p. 1582). 
No grupo respiratório ventral de neurônios estão os neurônios que permanecem quase inativos durante a respiração normal e tranquila, pois, não demonstram função rítmica no controle dela. Alguns neurônios do grupo ventral têm como responsabilidade favorecer a inspiração e expiração, por meio da estimulação elétrica, o que desencadeia sinais mais vigorosos para os músculos abdominais, no momento de excitação respiratória (GUYTON E HALL, 2017, p. 1585).

Além do centro respiratório, existe o sistema quimiorreceptor para o controle da respiração. Quimiorreceptores são receptores químicos neurais, importantes para a detecção de variações sanguíneas do $\mathrm{O}_{2}$, informando em menor escala sobre os níveis de concentração de $\mathrm{CO}_{2}$ e dos íons hidrogênio. Eles comunicam os sinais neurais para o centro respiratório encefálico, ajudando na regulação a atividade respiratória. Eles têm sua irrigação sanguínea individual, por meio de artéria diminuta, ligada de forma direta ao tronco arterial adjacente. Nesses corpos o fluxo sanguíneo é considerado extremamente alto, cerca de 20 vezes o peso dos próprios corpos, isso por minuto. Conclui-se que a porcentagem de $\mathrm{O}_{2}$ que é removido do fluxo sanguíneo é zerada, fazendo com que os quimiorreceptores sempre estejam expostos ao sangue arterial e, não ao sangue venoso (GUYTON E HALL, 2017, p. 1593).

\subsubsection{Memória e Atenção}

Memória é uma função cerebral complexa e encontra-se distribuídas por várias partes do cérebro, envolvendo complicados códigos eletroquímicos denominados engramas. Está intimamente ligada ao sistema límbico e às emoções. Em processo, ela desencadeia um conjunto de mudanças nas estruturas neuronais, desde os dendritos até às operadas nas sinapses, produzindo comunicação neuronal. (Fonseca, 2015, p. 66)

De acordo com a pesquisa inédita, realizada pela $\operatorname{Dr}^{\text {a }}$ Lívia Stocco Saches, neuropsicóloga do INCOR (Instituto do Coração) do Hospital das Clínicas da Faculdade de Medicina de São Paulo há a hipótese de que a falta de $\mathrm{O}_{2}$, pela complicação do SARS-CoV-2 pode causar comprometimentos cognitivos gerando falhas na memória e nas funções cognitivas. Essa pesquisa tinha como objetivo fazer uma amostra só com roo pacientes em casos assintomáticos, grau leve e grave, porém 
houve uma grande procura de pacientes e com eles, avalizar as sequelas causadas pelo vírus nas áreas cognitivas do Sistema Nervoso Central.

Cientistas da Cleveland Clinic, com o objetivo de entender a associação do covid-ı9 e as doenças neurodegenerativas como a demência e Alzheimer, realizaram, por meio de análise de dados de pacientes com Alzheimer e Covid-19 e com a utilização de inteligência artificial, um estudo para identificar a associação dessas doenças a partir da medição de proteínas e genes.

A análise abrangeu duas marcas de Alzheimer na situação cognitiva dos pacientes com características de lesões microvasculares e neuroinflamação o que possibilitou, a partir dessas características, constatar a forma, como e onde o SarsCov-2 provoca alterações cognitivas. Confirma-se então, que proteínas presentes no Sars-CoV-2 / Covid-19 permitem que o vírus ultrapasse a barreira hematoencefálica, que é uma estrutura de permeabilidade altamente seletiva que protege e bloqueia a entrada de substâncias neurotóxicas no sangue para o cérebro.

De acordo com os pesquisadores a,

\begin{abstract}
Covid-19 altera os marcadores de Alzheimer implicados na inflamação do cérebro e que certos fatores de entrada viral são altamente expressos nas células da barreira hematoencefálica. Essas descobertas indicam que o vírus pode impactar vários genes ou vias envolvidas na neuroinflamação e lesão microvascular do cérebro, o que pode levar ao comprometimento cognitivo semelhante à doença de Alzheimer. (Feixiong Cheng, membro do Instituto de Medicina Genômica da Cleveland Clinic) $)^{7}$
\end{abstract}

Vanessa Holanda, neurocirurgiã, diretora de Comunicação da Sociedade Brasileira de Neurocirurgia ( $\mathrm{SBN}$ ), sinaliza a importância das informações desse estudo que ajudam médicos a conduzir abordagens mais apropriadas para cada caso diante das sequelas que a Covd-I9 tem deixado no Sistema Nervoso Central (SNC).

Inúmeras patologias, inclusive a doença em questão, em que há a presença de sintomas de ansiedade e depressão em alguns casos, produz-se alterações no aspecto atencional do indivíduo. Seu aumento orienta-se para os estímulos negativos e ansiógenos da doença. Sua diminuição leva à dificuldade de memorização podendo evoluir para casos graves.

A atenção é o aspecto preponderante na formação da memória, permitindo que os dados recebidos do ambiente sejam isolados e gravados num banco de

\footnotetext{
${ }^{7}$ Redação Galileu (ver Referências)
} 
memória. Seu principal neurotransmissor é a Acetilcolina, cujos danos ou alterações, por exemplo, estão ligados aos déficits de memória no Alzheimer. A atenção necessita do estado de alerta ou Arousal que corresponde ao despertar dos sentidos e da vigilância ou Atenção Sustentada que é a persistência em algo por determinado período. Esses dois tipos pertencem ao $\mathrm{SARA}^{8}$, dentro da formação reticular e algumas de suas ligações, área frontal, sistema límbico, o tálamo e os glânglios basais.

Necessita ainda, da focalização ou Atenção Focalizada e Seletiva quando se elimina outros pontos de distração do campo do pensamento e atenção dividida. Esses tipos pertencem ao $\mathrm{SAP}^{9}$ cujas áreas cerebrais envolvidas são o córtex parietal posterior, o núcleo pulvinar lateral do tálamo e o colículo superior. A Atenção Seletiva, Sustentada e ividida também se relacionam ao $\mathrm{SAA}^{\mathrm{I0}}$ presente no cortex pré-frontal dorsolateral, córtex orbito-frontal, córtex cingulado anterior, área motora suplementária e núcleo caudado.

Os tipos mais comuns de atenção são: a bottom-up que refere ao recebimento do estímulo, decidindo seu significado e relevância para a permanência ou não; é primitiva, instintiva e dependente do tronco cerebral, dos neurotransmissores noradrenalina e glutamato e dos sistemas que ativam o estado de alerta e vigilância. A atenção Top-down inicia-se no córtex cerebral indo além dos mecanismos instintivos, promovendo a concentração ou foco mental pelo neurotransmissor GABA, ao ligar-se ao desejo e vontade do indivíduo, apesar de ser resultante do amadurecimento cerebral. É treinável desde a infância, em casa e escola. A de domínio específico agrupa vários tipos de atenção, localizando-se em áreas cerebrais ligadas à determinadas experiências sensoriais.

\section{RESULTADOS}

\section{I Perda de Memória e Covid}

Podemos observar alterações cognitivas e um aumento de casos de doenças neuropsiquiátricas vão ser comuns, devido ao fato da possível perda de neurônios por causa da doença. Dentre tais alterações, destacam-se: dificuldades de concentração

\footnotetext{
${ }^{8}$ Sistema Ativador Reticular Ascendente ou Rede de Alerta.

${ }^{9}$ Sistema Atencional Posterior ou Rede de Orientação.

ro Sistema Atencional Anterior ou Rede de Execução
} 
(ligada à atenção) e dificuldades e/ou perda de memória. Como o vírus ultrapassa a barreira hematoencefálica, barreira que seleciona, protege e bloqueia a entrada de substâncias no sangue para o cérebro, abre-se uma porta de entrada para as alterações cognitivas provocadas pela doença. Isso ocorre, dentre outros fatores, porque o vírus utiliza-se dos astrócitos, como um veículo, para infectar o cérebro, pois, esses expressam a proteína $\mathrm{ACE} 2$ e é a ela que o vírus "se agarra".

Os astrócitos são células neurogliais que trabalham na proteção, nutrição e sustentação dos neurônios pela corrente sanguínea; na modulação da respiração liberando ATP (receptor específico neuronal de controle da respiração e com potencial energético), na função de evitar as substâncias nocivas, inclusive o vírus, na busca da homeostase do SNC, na captação e liberação de neurotransmissores regulando-os, dentre outras funções. Se envolvem na regulação do fluxo sanguíneo cerebral e do acoplamento neurovascular, e atuam na imunidade, por meio da síntese e secreção de diversas citocinas inflamatórias. Apresentam impacto no controle energético cerebral, pois fornecem energia e metabólitos (Rouach et al., 2008).

A Proteína $\mathrm{ACE}_{2}{ }^{\mathrm{II}}$ (a quem o Sars-Cov-2 se "agarra") responsável por promover a vasodilatação e diminuir a pressão arterial, quando se expressa de forma reduzida, contribui para elevação da permeabilidade vascular, do edema pulmonar, da proliferação dos neutrócitos piorando o quadro do paciente. Ela está presente nas mais abundantes neuroglias, os astrócitos, que é um receptor (porta de entrada) do vírus e paradoxalmente é a proteína que tem efeito protetor contra danos pulmonares causados por infecções virais. Há em um subconjunto de DRG, neurônios que contém a $\mathrm{ACE} 2$, que representa um portal para o vírus (YANO \& ABREU, 2021). De acordo com os autores,

\footnotetext{
Os neurônios DRG específicos que continha $\mathrm{ACE} 2$ também tinha as instruções genéticas, mRNA, para uma proteína sensorial chamada MRGPRD. Esta proteína marca as células como um subconjunto de neurônios cujas terminações estão concentradas nas superfícies do corpo - a pele e os órgãos internos, incluindo os pulmões - onde eles seriam posicionados para capturar o vírus. Desta forma, a infecção do nervo pode contribuir para doenças agudas, bem como sintomas duradouros.
}

\footnotetext{
${ }^{\text {II }} \mathrm{ACE}_{2}$ - receptor da enzima conversora da angiotensina humana 2.
} 
Diante disso, os neurônios sensoriais sendo infectados pelo vírus, traz consequências à longo prazo, mesmo que esse não permaneça nas células. As Citocinas de pacientes infectados interagem com os receptores neuronais e por isso, a presença dos inúmeros sintomas cerebrais inclusive a desatenção e as alterações na memória. (PRICE 2020)

A Citocina TGF -Bié uma das moléculas sinaptogênicas derivadas dos astrócitos que induz a síntese e secreção do neuromodulador $\mathrm{D}$ Serina. Esse neuromodulador é um d-aminoácido, receptor do NMDA (Fossat et al., 20ir), envolve-se na LTP, na plasticidade sináptica e memória (Yang et al., 2003; Henneberger et al., 2010); potencializa a memória de longa duração, a memória de trabalho, a aprendizagem e sua deficiência, como por exemplo, a provocada pela entrada de um vírus como o Sars- $\mathrm{CoV}-2$ pode incidir em déficits cognitivos e sinápticos (Devito, et al., 20II), por isso a perda da memória relatada nos inúmeros estudos de casos.

Diante da injúria do vírus, os astrócitos se tornam reativos, em vez de exercer efeito protetor, possibilitam a perda sináptica e morte neuronal, pois não conseguem, por exemplo, captar a ERO (espécies reativas do oxigênio fato que pode ser associado a doenças no trato respiratório), ficando evidente em doenças degenerativas (AVC, neurotoxicidade no HIV, Esclerose Lateral Amiotrófica (ELA)), dentre outras. Por outro lado, eleva-se a concentração do GABA - glutamato extracelular provocando a perda sináptica e morte neuronal (Rao et al., 2003) Na ELA, por exemplo, por causa dos astrócitos reativos, há a redução da capacidade de transporte do glutamato. Neurônios que morrem liberam mais glutamato, ativam mais receptores e promovem injúria neuronal em ciclo. No circuito neuronal (o potencial de ação) em conjunto com o circuito glial (ondas de cálcio) percebe-se a função cerebral de produção de pensamentos, emoções humanas e memória.

As células gliais ou neuroglias como por exemplo, os astrócitos, suas ligações sinápticas, as múltiplas potencialidades de regeneração celular, nos axônios e nos dendritos é que constituirão a plasticidade neuronal, tão necessária para a manutenção e desenvolvimento da memória. 


\subsection{Neuroplasticidade e Ginástica Cerebral}

É sabido que o SNC é adaptável e pode promover modificações morfológicas e funcionais em resposta a alterações ambientais ou injúrias provocadas, por doenças, lesões ou acidentes que impactem diretamente o cérebro. Por meio de estímulos e treinos cognitivos recupera-se ou potencializa-se funções corrompidas, mesmo que haja deslocamento de áreas neuronais para assumirem outras funções. O cérebro é plástico, adaptável, mesmo sendo um cérebro adulto e pronto. A essa capacidade de alteração para adaptação é que chamamos de neuroplasticidade ou plasticidade neural.

Quando praticamos exercícios de desafio mental, ativamos o hipocampo, estrutura localizada nos lobos temporais - que têm papel decisivo na consolidação de lembranças pois, é o local onde acontece uma conversão da informação de memória curta e de longa duração, sendo que o córtex frontal participa dessa memorização de acordo com a "idade" dessa memória. Os arquivamentos mentais são mediados por emoções, quando maior a identificação e nível e qualidade da emoção, maior chance de consolidar memória. O hipocampo arquiva memórias e com o passar do tempo, as mais importantes passam para o arquivo do lobo frontal, lugar de memórias mais antigas.

A perda de memória é relatada em muitos casos de pacientes recuperados da Covid-19, em alguns pode ser irreversível como qualquer modificação no organismo, mas o cérebro é plástico, podendo recuperar o funcionamento mediante práticas que favoreçam a neuroplasticidade.

\section{CONSIDERAÇÕES FINAIS}

Os resultados das pesquisas e estudos de casos aqui apresentados sugerem que o SARS- CoV-2 pode impactar negativamente a vida do paciente no que se refere à memória em até após 8 meses mesmo tendo recuperado da doença e a tido em grau leve, associado a um agravamento da saúde. À nível cerebral, as estruturas ligadas ao córtex responsável pela memória, atenção, linguagem e consciência são as mais afetadas demonstrando diminuição na espessura ou aumento, provavelmente por edema. 
As mitocôndrias dos astrócitos, responsáveis pela produção de energia para os neurônios, se alteram devido a diminuição dos níveis de piruvirato e lactato (substratos energéticos) e com isso, consomem mais glicose, influenciando diretamente na expressão dos neurotransmissores Glutamato (excitatório e relativo à memória e aprendizagem) e do GABA (inibidor do disparo excessivo que promove a calma e o relaxamento). Ao tentar manter o nível de energia suficiente para os neurônios, os astrócitos diminuem sua potência da ação protetora. Consequentemente, astrócitos infectados diminuem a efetividade dos neurônios desencadeando morte neuronal.

Considera-se de extrema importância para avaliação e tratamento das alterações atencionais e de memória que incapacitam o indivíduo tornando o disfuncional, em casos de pacientes recuperados da Sars- CoV-2, uma completa avaliação neuropsicológica que inclui a medição de tempo de resposta, a flexibilidade cognitiva, a velocidade do processamento, a inibição, a monitorização, a coordenação, a percepção visual, possíveis por meio de testes como: Teste de Stroop, TOVA, VOT, CPT dentre outros, a fim de promover a neuroplasticidade.

Neuroplasticidade, no caso da Covid-ı́ não significa neurogênese, porém, a atenção e a memória podem ser melhoradas e reabilitadas aumentando com isso tal plasticidade. Decorrente disso, a estimulação cognitiva, por meio de diversas atividades e hábitos são importantes na plasticidade cerebral, pois, essa é a base da reabilitação da atenção, da memória e de inúmeras capacidades cognitivas.

Exercícios para melhorar a função cognitiva podem ajudar a combater o problema, a depender do caso, pode ser necessário o uso de medicamentos e/ou suplementação. O treinamento cerebral envolve aprender coisas novas, saindo da zona de conforto com mudança de hábitos, exercícios, dieta direcionada à memória, exercícios de lógica e jogos de memória, atividades diversificadas, que promovam a manutenção do foco atencional, que desenvolvam, portanto, a memória, criando hábitos saudáveis, oxigenando o cérebro, fomentando a cognição. Para não esquecer é preciso: exercitar a atenção, organizar ideias, trabalhar com a emoção, repetir e revisar.

Exercícios que promovem a neuroplasticidade:

I- Faça percursos habituais, de forma diferente. 
Troque o caminho, vá a pé, de ônibus, de trem, de bicicleta... altere a rota.

2- Troque objetos de lugar.

3- Aprenda um novo idioma.

4- Se é destro, use mais a mão esquerda e vice-versa.

5- Aprenda a toca um instrumento.

6- Ouça música tentando identificar os instrumentos musicais.

7-Decore músicas novas.

8- Desenvolva o paladar com alimentos naturais e diferentes do cardápio habitual.

9- Leia mais.

ıo-Palavras cruzadas

II- Jogos de tabuleiro

12- Atividade física

É preciso considerar dentro do fenômeno da neuroplasticidade que a questão da alimentação saudável é imprescindível para a conquista do equilíbrio mental, melhoria da memória e prevenção de doenças. (Crystal, 2020)

\section{REFERÊNCIAS}

ACADEMIA BRASILEIRA DE NEUROLOGIA. Perda de memória persistente em pacientes recuperados da covid-ıs intriga médicos. Rio Grande do Sul. Atualizado em 12 de janeiro de 2021. Disponível em https://www.abneuro.org.br/post/perda-de-mem\%C3\%B3ria-persistente-empacientes-recuperados-da-covid-ı-intriga-m\% $\mathrm{C}_{3} \%$ A9dicos Acessado em $\mathrm{I}_{4} \mathrm{de}$ outubro de 2021.

CPAH. 30\% dos pacientes graves de covid-19 apresentam sintomas neurológico. 09 de agosto de 2021. Disponível em:https://cpah.com.br/2021/o8/o9/30-dos-pacientesgraves-de-covid-I9-apresentam-sintomas-neurologicos/ <Acesso:12/10/202I >

CRYSTAL, J.D. Memory: Amyloid Beta Is Good Before It Is Bad. Curr Biol. v. 30, n. Io, págs. 449-450, 2020. doi:10.1016/j.cub.2020.03.024.

CRUNFLI ET AL. (2020) O SARS-CoV-2 infecta astrócitos cerebrais de pacientes com COVID-19 e prejudica a viabilidade neuronal. medRxiv 2020.10.09.20207464; doi: https://doi.org/I0.IIoI/2020.10.09.20207464 
DE ERAUSQUIN, GA, SNYDER, H, CARRILlO, $\mathrm{M}$, et al. As sequelas neuropsiquiátricas crônicas de COVID-19: A necessidade de um estudo prospectivo do impacto viral no funcionamento do cérebro. Alzheimer's Dement. 2021; 17: 1056 1065. https://doi.org/10.1002/alz.12255

DEVITO, L. M. et al. Serine racemase deletion disrupts memory for order and alters cortical dendritic morphology. Genes Brain Behav., v.10, n.2, p.210-22, 2011.

FONSECA. V. da. Cognição, neuropsicologia e aprendizagem: abordagem neuropsicológica e psicopedagógica. Petrópolis, RJ. Vozes, 2015.

FOSSAT, P., et al. Glial D-serine gates NMDA receptors at excitatory synapses in prefrontal cortex. Cereb Cortex. v.22, n.3, p.595-606, 2012.

GOMES. F. C. A., TORTELLI. V. P., DINIZ. L. Glia: dos velhos conceitos às novas funções de hoje e as que ainda virão. Estudos Avançados27 (77), 2013.

GUYTON \& HALL. Tratado de Fisiologia Médica. Tradutor Jonh E. Hall. Rio de Janeiro: Elsevier Editora Ltda, I3ª edição, 2016.

HENNEBERGER, C. et al. Long-term potentiation depends on release of D-serine from astrocytes. Nature, v.14, 463, n.7278, p.232-62, 2010.

HUSSAIN. M. JABEEN. N., RAZA. F., SHABBIR. S., BAIG. A.A., AZIZ. A.A. \& B. Structural Variations in Human ACE2 may Influence its Binding with SARSCoV-2 Spike Protein. Journal of Medical Virology. https://doi.org/Io.1002/jmv.25832.

https://onlinelibrary.wiley.com/doi/ro.1002/jmv.25832 > acesso em 07/10/2021.

MAO. L., WANG. M., CHEN. S., HE. Q., CHANG. J., HONG. C., ZHOU. Y., WANG. D., LI. Y., JIN. H., HU. B. Manifestações neurológicas de pacientes hospitalizados com COVID-19 em Wuhan, China: um estudo retrospectivo de série de casos. medRxiv, 02.22.20026500; doi: https://doi.org/I0.110I/2020.02.22.20026500 
PRE prints. Neurological Complications of Pandemic COVID-19: What have we got só far? 17 april de 2020. Disponível: https://www.preprints.org/manuscript/202004.0304/vi

$\langle$ Acesso: $13 /$ 12/2021 $>$

PRICE et al. 2020. A pharmacological interactome between COVID-r9 patient samples and human sensory neurons reveals potential drivers of neurogenic pulmonary dysfunction, Brain, Behavior, and Immunity, Volume 89, October, Pages 559-568.

RAO, T. S. et al. Glutamate-dependent glutamine, aspartate and serine release from rat cortical glial cell cultures. Brain Res., v.18, 978, n.I-2, p.213-22, 2003.

Redação Galileu. Em estudo, II\% têm problemas de memória 8 meses após Covid-ı9 leve. Atualizado em 30 de julho de 2021. Disponível em https://revistagalileu.globo.com/Ciencia/Saude/noticia/2021/o7/em-estudo-II-temproblemas-de-memoria-8-meses-apos-covid-ı-leve.html <Acesso i4 de outubro de 202I>.

RIGATTO. K.V., BOHLKE. M., IRIGOYEN. M. C. SISTEMA RENINAANGIOTENSINA: da Fisiologia ao Tratamento. Revista da Sociedade de Cardiologia do Rio Grande do Sul - Ano XIII no 03 Set/Out/Nov/Dez 2004

RODRIGUES. F. de A. Relação entre a fadiga, dependência de dopamina com as disfunções neuronais. Braz. J. of Develop., Curitiba, v. 6, n. II, p. 85183-85194, nov. 2020 .

ROUACH, N. et al. Astroglial metabolic networks sustain hippocampal synaptic transmission. Science, v.5, 322, n.5907, p.1551-5, 2008.

SILVA. A.A., GONÇALVES. R.C. Espécies reativas do oxigênio e as doenças respiratórias em grandes animais. Ciência Rural, Santa Maria, v. 40, n. 4, p. 994-Ioo2, 2010. 
SILVERTHRN, Dee Unglaub. Fisiologia Humana: uma abordagem integrada. Porto Alegre - Rio Grande do Sul, $7^{\text {a }}$ edição, Artmed Editora LTDA, 2017.

SORAAS, Arne, et al. Self-reported memory problems 8 months after covid-19 infection. Jama Netw Open, 2021, 4 (7) Disponível em https://jamanetwork.com/journals/jamanetworkopen/fullarticle/278253I

$<$ Acesso: 25 de outubro de 2021 $>$.

VAlEntiN. et al. O Uso Do Jogo Digital Mentalplus Para O Rastreio Na Identificação De Dificuldades De Aprendizagem: Uma Pesquisa De Campo. Revista Científica da FHO| Fundação Hermínio Ometto v.7, n.I/2org.

VALENTIN. L. S.S. (2021). Estudo inédito no mundo realizado no InCor mostra que pacientes que tiveram Covid-ı podem sofrer disfunções cognitivas. São Paulo: News Release, InCOR - HCFMUSP.

YANG, Y. et al. Contribution of astrocytes to hippocampal long-term potentiation through release of D-serine. Proc. Natl. Acad. Sci. USA., v.9, Ioo, n.25, p.15194-9, 2003.

YANO, R., RODRIGUES, F. de A. Covid-19 - Risks To The Central Nervous System And Cardiovascular Damage. International Journal of Development Research Vol. II, Issue, 02, pp. 4426I-44264, February 202I https://doi.org/I0.37118/ijdr.21006.02.2021. 